\title{
Effects of steroid-impregnated middle meatal packing on the postoperative outcome after endoscopic sinus surgery
}

\author{
Husam Talib Dakhil', Muhanned Moussa Alwan', Nassr Abdulsalam Mohammed ${ }^{2}$ \\ ${ }^{1}$ ENT Department, Al-Imamain Al-kadhimyain Teaching Medical City, Baghdad Al Karkh Health Directorate, \\ Ministry of Health/Environment, Baghdad, Iraq \\ ${ }^{2}$ Baiji General Hospital, Salahuddin Health Directorate, Ministry of Health/Environment, Tikrit, Iraq
}

\section{ABSTRACT}

OBJECTIVE. To evaluate the effects of steroid-impregnated middle meatal packing on post-operative outcome after endoscopic sinus surgery.

MATERIAL AND METHODS. We performed a prospective clinical study on 26 randomly selected patients, older than 12 years, with chronic rhinosinusitis, who failed medical management and who were operated on by endoscopic sinus surgery at Al-Imamain Al-Kadhimyain Teaching Medical City over a period of 12 months. Patients were divided into two groups: the 1st with middle meatal packing soaked with steroids (triamcinolone) and the 2nd group with middle meatal packing alone, without steroid. The two study groups were followed-up postoperatively for adhesions, crustations and nasal discharge over a period of three months.

RESULTS. The study showed a significant reduction in early nasal crustations ( $p$-value $=0.048$ ) and nasal discharge ( $p$-value $=0.033$ ) after endoscopic sinus surgery in patients who received triamcinolone-impregnated middle meatal packing. Synechia formation was significantly lower in the steroid-impregnated group one month after surgery ( $\mathrm{p}$-value=0.021), but no difference at one week ( $\mathrm{p}$ value $=0.089)$. At the three-month follow-up, comparing the two groups, the following variables were not statistically significant: crusts ( $\mathrm{p}$-value $=0.22)$, nasal discharge $(\mathrm{p}$-value $=0.26)$, synechia $(\mathrm{p}$-value $=0.074)$.

CONCLUSION. There are significant reductions in the incidence of early crustations, synechia, nasal discharge in patients who received triamcinolone middle meatal packing following endoscopic sinus surgery.

KEYWORDS: steroid-impregnated pack, sinus surgery, middle meatal, nasal discharge.

\section{INTRODUCTION}

The treatment of choice for intractable rhinosinusitis are antrostomies and Caldwell-Luc procedures, but in the last decade these two procedures have been replaced by endoscopic sinus surgery (ESS $)^{1}$. The synechiae, middle meatal obstruction, infection, and chronic inflammation are factors for poor surgical outcomes ${ }^{1}$. The most important area for normal mucociliary drainage of the paranasal sinuses is the osteomeatal complex ${ }^{2}$. A limited number of diseases in the osteomeatal complex can obstruct the narrow drainage pathways of the frontal, ethmoid and maxillary sinuses, producing a much more florid disease within the cavity of the sinuses. The aim of functional endoscopic sinus surgery (FESS) is to eradicate the disease in the osteomeatal complex by removing as little mucosa as possible, thereby restoring natural ventilation and mucociliary drainage of the frontal, ethmoid and maxillary sinuses, and reversing any mucosal change within the sinuses ${ }^{3}$.

The ESS had been used for the treatment of several conditions ${ }^{4}$. Without doubt, the most common post-operative complications are synechiae, therefore meticulous postoperative care is mandatory ${ }^{5}$. The optimal surgical outcomes are obtained by preserved good patency of the middle meatus and 
Table 1. The association between the studied groups and postoperative evaluation criteria after one week.

\begin{tabular}{|c|c|c|c|c|}
\hline \multirow{2}{*}{$\begin{array}{l}\text { Evaluation one week } \\
\text { postoperatively }\end{array}$} & \multicolumn{2}{|c|}{ Study Group } & \multirow{2}{*}{$\begin{array}{c}\text { Total } \% \\
n=52\end{array}$} & \multirow{2}{*}{$\mathrm{P}$-value } \\
\hline & Group A (\%) $n=26$ & Group B (\%) $n=26$ & & \\
\hline \multicolumn{5}{|l|}{ Crustations } \\
\hline Yes & $3(25.0)$ & $9(75.0)$ & $12(23.1)$ & \multirow{2}{*}{0.048} \\
\hline No & $23(57.5)$ & $17(42.5)$ & $40(76.9)$ & \\
\hline \multicolumn{5}{|l|}{ Nasal discharge } \\
\hline Absent & $18(66.7)$ & $9(33.3)$ & $27(51.9)$ & \multirow{3}{*}{0.033} \\
\hline Thin & $6(37.5)$ & $10(62.5)$ & $16(30.8)$ & \\
\hline Thick & $2(22.2)$ & $7(77.8)$ & $9(17.3)$ & \\
\hline \multicolumn{5}{|l|}{ Synechia formation } \\
\hline Yes & $3(27.3)$ & $8(72.7)$ & $11(21.2)$ & \multirow{2}{*}{0.089} \\
\hline No & $23(56.1)$ & $18(43.9)$ & $41(78.8)$ & \\
\hline
\end{tabular}

good surgical technique ${ }^{6}$. There are different basic criteria for products to be used as nasal packing ${ }^{6}$.

In both preoperative and postoperative stages, intranasal topical corticosteroids have been used to treat chronic rhinosinusitis (CRS), to improve both the symptoms of patients and rate of recurrence $^{7}$. The edema of the sinonasal mucosa can be reduced by topically applying of Triamcinolone, which leads to reduction in crusting and improves wound healing ${ }^{8,9}$.

The study aimed to evaluate the effect of steroidimpregnated middle meatal packing after endoscopic sinus surgery on nasal crusting and synechiae compared to Merocel ${ }^{\circledR}$ alone.

\section{MATERIAL AND METHODS}

\section{Study design and sample}

We performed a prospective study on 26 randomly selected patients with chronic rhinosinusitis operated on endoscopic sinus surgery at Al-Imamain Al-Kadhimain Teaching Medical City, over a period of 12 months from August 2017 to September 2018. The patients were divided into two groups: Group A included 13 patients (26 nostrils) with steroid-impregnated middle meatal packing; Group B included 13 patients (26 nostrils) with Meroce ${ }^{\circledR}$ middle meatal packing without steroid.

\section{Inclusion criteria}

1. Patients aged from 12 years old to 51 years old.

2. Patients with signs and symptoms of chronic rhinosinusitis refractory to maximal medical management. In addition to any of endoscopic signs:
- Middle meatus mucopurulent discharge

- Middle meatus edema

- or CT changes: mucosal changes within the osteomeatal complex and/or sinuses.

3. Bilateral Disease.

Exclusion criteria

1. Patients with allergic rhinitis.

2. Immunocompromised patients.

3. Patients with nasal polyposis.

4. Revision surgery.

5. Patients with unilateral rhinosinusitis.

Ethical considerations

All patients who participated in this work were consented about the nature and the procedure of this thesis and the surgery and its complications.

\section{Surgical technique}

After completion of the required steps of FESS, the patients were divided into two groups for nasal packing:

- In Group A patients: 1 ampoule of triamcinolone acetonide $40 \mathrm{mg} / \mathrm{ml}$ and a Polyvinyl alcohol (PVA) coated nasal packing made from Merocel $^{\circledR}$ $2 \mathrm{~cm}$ was inserted with endoscopic guidance into the middle meatus for $48 \mathrm{hrs}$.

- In Group B patients: the PVA Merocel ${ }^{\circledR}$ pack with the same dimensions was inserted with endoscopic guidance into the middle meatus, without steroid, and removed 48 hours postoperatively.

\section{Postoperative care}

Follow-up visits were performed for all patients every week in the first month postoperatively, twice in the second month and once in the third month.

Endoscopic assessment of the nose with suction clearance of any secretion and removal of any dead tissues found, division of the adhesions, was done 
under local anaesthesia.

Crustations, synechia, nasal discharge were evaluated according to the postoperative endoscopy.

\section{Statistical analysis}

The data were analysed using the Statistical Package for Social Sciences (SPSS) version 25. The mean, standard deviation and ranges were used. Categorical data were presented by frequencies and percentages. The independent t-test (two tailed), Ztest and Pearson's Chi-square test were used. A $p$ value less than 0.05 was considered significant.

\section{RESULTS}

The total number of study patients was 26 (52 nostrils). All of them were diagnosed with chronic rhinosinusitis and operated by endoscopic sinus surgery. They were divided into two groups: Group A included 13 patients (26 nostrils) with steroidimpregnated middle meatal packing and group B included 13 patients (26 nostrils) with Merocel $^{\circledR}$ middle meatal packing without steroid.

\section{Postoperative evaluation}

One week postoperatively. The association between the studied groups and postoperative evaluation criteria after one week is shown in Table 1 . Crustations were observed in 12 nasal fossae (23.1\%), 9 sides were in group B and 3 nasal sides were found in group A. The difference between the two groups was statistically significant due to the proinflammatory effects of triamcinolone impregnated in the middle meatal packing $(p$-value $=0.048)$.

Thin nasal discharge was seen in 16 nasal fossae;
$62.5 \%$ of them were in group B and $37.5 \%$ of them were in group A. Thick nasal discharge was found in 9 nasal sides, 7 (77.8\%) being included in group B and $2(22.2 \%)$ in group A, the difference between the two groups being significant in favour of group A $(p$-value $=0.033)$.

Synechiae were found in 11 nasal fossae, of which 8 sides were in group B and 3 sides were in group A. With a $p$-value of 0.089 , we can state that there was no statistically significant difference between the study groups in what the synechiae formation is concerned.

One month postoperatively. The association between the studied groups and postoperative evaluation criteria after one month is shown in Table 2. We noticed that $73.3 \%$ of the patients with crustations did not receive steroid-impregnated middle meatal packing during the surgical procedure $($ Group B $)$, with a significant association $(p$-value $=$ 0.032 ) between postoperative crustations after one month and using steroid-impregnated middle meatal packing during the procedure.

Regarding synechiae formation, at the onemonth follow-up, $87.5 \%$ of patients with synechiae formation did not use steroid-impregnated middle meatal packing during the procedure (Group B), with a significant association $(p$-value $=0.021)$ between postoperative synechiae formation after one month and using steroid-impregnated middle meatal packing during the procedure.

There was no statistically significant association $(p$-value $=0.097)$ between postoperative nasal discharge after one month and using steroid-impregnated middle meatal packing during the procedure.

Three months postoperatively. Crusts were ob-

Table 2. The association between studied groups and postoperative evaluation criteria after one month.

\begin{tabular}{|c|c|c|c|c|}
\hline \multirow{2}{*}{$\begin{array}{l}\text { Evaluation one month } \\
\text { postoperatively }\end{array}$} & \multicolumn{2}{|c|}{ Study Group } & \multirow{2}{*}{$\begin{array}{c}\text { Total } \% \\
n=52\end{array}$} & \multirow{2}{*}{ P-value } \\
\hline & Group $A(\%) n=26$ & Group B (\%) $n=26$ & & \\
\hline \multicolumn{5}{|l|}{ Crustations } \\
\hline Yes & $4(26.7)$ & $11(73.3)$ & $15(28.8)$ & \multirow{2}{*}{0.032} \\
\hline No & $22(59.5)$ & $15(40.5)$ & $37(71.2)$ & \\
\hline \multicolumn{5}{|l|}{ Nasal discharge } \\
\hline Absent & $20(60.6)$ & $13(39.4)$ & $33(63.5)$ & \multirow{3}{*}{0.097} \\
\hline Thin & $2(22.2)$ & $7(77.8)$ & $9(17.3)$ & \\
\hline Thick & $4(40)$ & $6(60)$ & $10(19.2)$ & \\
\hline \multicolumn{5}{|l|}{ Synechia formation } \\
\hline Yes & $1(12.5)$ & $7(87.5)$ & $8(15.4)$ & \multirow{2}{*}{0.021} \\
\hline No & $25(56.8)$ & $19(43.2)$ & $44(84.6)$ & \\
\hline
\end{tabular}


Table 3. The association between studied groups and postoperative evaluation criteria after three months.

\begin{tabular}{|c|c|c|c|c|}
\hline \multirow{2}{*}{$\begin{array}{c}\text { Evaluation three month } \\
\text { postoperatively }\end{array}$} & \multicolumn{2}{|c|}{ Study Group } & \multirow{2}{*}{$\begin{array}{c}\text { Total } \% \\
n=52\end{array}$} & \multirow{2}{*}{ P-value } \\
\hline & Group A (\%) n= 26 & Group B (\%) n= 26 & & \\
\hline \multicolumn{5}{|l|}{ Crustations } \\
\hline Yes & $2(28.6)$ & $5(71.4)$ & $7(13.5)$ & \multirow{2}{*}{0.22} \\
\hline No & $24(53.3)$ & $21(46.7)$ & $45(86.5)$ & \\
\hline \multicolumn{5}{|l|}{ Nasal discharge } \\
\hline Absent & $22(56.4)$ & $17(43.6)$ & $39(75)$ & \multirow{3}{*}{0.26} \\
\hline Thin & $3(33.3)$ & $6(66.7)$ & $9(17.3)$ & \\
\hline Thick & $1(25.0)$ & $3(75.0)$ & $4(7.7)$ & \\
\hline \multicolumn{5}{|l|}{ Synechia formation } \\
\hline Yes & $0(0)$ & $3(100.0)$ & $3(5.8)$ & \multirow{2}{*}{0.074} \\
\hline No & $26(53.1)$ & $23(46.9)$ & $49(94.2)$ & \\
\hline
\end{tabular}

served in only 7 nasal sides $(13.5 \%), 5$ sides $(71.4 \%)$ being seen in group B while 2 sides $(28.6 \%)$ were in group A. With a $p$-value of 0.22 , we state that there was no significant correlation between the use of steroid-impregnant middle meatal packing and crusts formation three months after surgery (Table 3 ).

Thin nasal discharge was seen in 9 nasal sides $(17.3 \%), 6$ in group B and 3 sides in group A, while thick nasal discharge was seen in only 4 sides $(7.7 \%)$ - 3 of them were in group B and only one was in group A (Table 3). Three months after surgery, we found no significant correlation between the use of steroid-impregnated middle meatal packing and the type of nasal discharge ( $p$-value $=0.26)$.

Synechiae were found in only 3 nasal fossae $(5.8 \%)$, all being present in patients included in Group B ( $p$-value $=0.074)$.

We can sustain that the present study showed no significant associations regarding the crusts, nasal discharge and synechiae 3 months after surgery, and that is mainly because the steroid-impregnated packing does not remain long enough in the middle meatus to influence the long-term local inflammatory response.

\section{Postoperative discomfort or pain}

Table 4 shows the association between discomfort or pain on postoperative removal of pack and using of steroid in middle meatal packing during the surgical procedure. There was no significant association $(p$-value $=0.543$ ) between discomfort or pain on postoperative removal of pack and using of steroid-impregnated middle meatal packing in the procedure, although steroids can reduce edema around the packing and may reduce the pain upon its removal.

\section{DISCUSSIONS}

The most common complications of FESS are postoperative synechiae and crusting formation ${ }^{10-13}$. The incidence ranged from $1 \%$ to $36 \%{ }^{10-13}$.

Table 4. The association between discomfort or pain on postoperative removal of pack and using of steroid-impregnated middle meatal packing in the procedure.

\begin{tabular}{|c|c|c|c|c|}
\hline \multirow{2}{*}{ Discomfort and Pain } & \multicolumn{2}{|c|}{ Study Group } & \multirow{2}{*}{$\begin{array}{c}\text { Total } \% \\
n=52\end{array}$} & \multirow{2}{*}{$P$-value } \\
\hline & Group A (\%) $n=26$ & Group B (\%) $n=26$ & & \\
\hline Mild & $6(66.7)$ & $3(33.3)$ & $9(17.3)$ & \multirow{3}{*}{0.543} \\
\hline Moderate & $11(45.8)$ & $13(54.2)$ & $24(46.2)$ & \\
\hline Severe & $9(47.4)$ & $10(52.6)$ & $19(36.5)$ & \\
\hline
\end{tabular}


Topical intranasal corticosteroids are used to control patients' symptoms in $\mathrm{CRS}^{14}$. Those topical steroids will cause higher drug concentrations locally, systemic absorption will be minimal, and systemic side effects will be reduced ${ }^{15,16}$.

The results of this study showed that in the first postoperative week, 12 nasal fossae presented crustations $(23.1 \%), 25 \%$ of them being in Group A, while $75 \%$ of them in Group B, with a $p$-value of 0.048 . This result was also seen during the 1st month follow-up, with 15 sides which had crustations (28.8\%), 26.7\% of them being included in Group A and $73.3 \%$ in group B $(p$-value $=0.032)$. At the 3-month follow-up, we found that there was no significant correlation between the use of steroid-impregnated middle meatal packing and crusts formation $(p$-value $=0.22)$. Only 7 nostrils still presented crusts, 2 of them being included in Group A $(28.6 \%)$ and 5 in Group B $(71.4 \%)$. Our results are similar to those found in the literature. Sabarinath et al. ${ }^{8}$ study results showed that $42.7 \%$ of the cases had crustations in the first postoperative week, of which $25 \%$ in group A, while the remaining $75 \%$ in group B and a $p$-value of 0.001 . One month postoperatively, crustations were seen in $22.7 \%$ of the cases, $29.4 \%$ of them seen in group A and $70.5 \%$ of them were in group B ( $p$-value $=0.039)$. 3 months postoperatively, cursts were found in $21.3 \%$ of the cases. $25 \%$ of them were included in group A and $75 \%$ of them in group B, with a $p$-value of 0.08 . In the study performed by Huwang et al. ${ }^{7}$, the crustations were seen after 8 weeks postoperatively with a mean of $0.39 \pm 0.52$ vs. $0.53 \pm 0.68$ in groups $A$ and $B$, respectively.

Evaluating the presence of nasal discharge, the follow-up performed one week after surgery revealed thin and thick nasal discharge in 25 nasal fossae, 8 being included in Group A and 17 in Group B $(p$-value $=0.032)$. One month postoperatively, only 19 nasal fossae of 52 presented nasal discharge, 6 of them in Group A and 13 in Group B ( $p$-value = $0.097)$. Three months postoperatively, there were 39 nostrils $(75 \%)$ with no secretions and $13(25 \%)$ with thin and thick nasal discharge $(p$-value $=0.26)$. Of the 13 nostrils with present nasal discharge, 4 were included in Group A and 9 in group B. Considering these results, we conclude that the correlation between the presence or absence of nasal discharge and the use of steroid-impregnated middle meatus packing is statistically significant till three months after surgery. There are also studies which report no significant difference between the use or non-use of steroid-impregnated middle meatus packing after FESS and the type and presence of nasal discharge. Sabarinath et al. ${ }^{8}$ reported in their study from 2017 that one month after surgery $81.3 \%$ of the patients had thin nasal discharge equally divided between the two groups, with no case with thick nasal discharge $(p$-value $>0.05)$. At the one-month and threemonth follow-ups, they found no statistical correlation, even if there was a decrease in the number of nostrils with secretions $(24.1 \%$ at one month $-33.3 \%$ in group $\mathrm{A}$ and $66.6 \%$ in group $\mathrm{B}, p$-value $>$ $0.05 ; 4 \%$ at three months $-25 \%$ in group $\mathrm{A}$ and $75 \%$ in group $\mathrm{B}, p$-value $>0.05)^{8}$.

Another important parameter evaluated in our study was the synechiae formation. During the follow-up, synechiae were absent in the majority of nasal fossae $(78.8 \%$ at one week, $84.6 \%$ at one month, $94.2 \%$ at three months). The presence of synechiae was preponderant in Group B, those nostrils without steroid-impregnant middle meatal packing. Three months after surgery, all 3 nostrils with synechiae were included in Group B. From the statistical point of view, there was a statistically significant correlation between the presence or absence of synechiae and the steroid-impregnated middle meatus packing only one month postoperatively $(p$-value $=0.021)$. Comparing our results with those found in the literature, Hwang et al. ${ }^{7}$ report a significant difference in what the middle turbinate synechiae with the lateral wall are concerned ( $p$-value $=0.037)$ between the two groups eight weeks after surgery.

During the nasal packing removal in this study 48 hours postoperatively, pain and discomfort was mild in $17.3 \%$ of the patients, $66.7 \%$ in Group A and $33.3 \%$ in Group B; moderate in $46.2 \%$ of the cases, $45.8 \%$ in Group A and $54.2 \%$ in Group B; severe in $36.5 \%$; with $p$-value of 0.543 . The pain and discomfort during packing removal in the study performed by Chang et al. ${ }^{17}$ in 2011 resulted in a higher discomfort in the budesonide-soaked Merocel MMS, with a mean score $=3.93 \pm 1.44$ for the medication group and a mean score of $3.47 \pm$ 1.6 in the control group ( $p$-value $=0.37)$.

\section{CONCLUSIONS}

Early nasal crustations, synechiae and nasal discharge after endoscopic sinus surgery for the treatment of chronic rhinosinusitis are reduced by the use of triamcinolone-impregnated middle meatal packing. We recommend longer study time, larger populations in the study group, and alternating nasal cavities of the same patient.

Conflict of interest: The authors have no conflict of interest to disclose.

Contribution of authors: All authors have equally contributed to this work. 


\section{REFERENCES}

1. Côté DW, Wright ED. Triamcinolone-impregnated nasal dressing following endoscopic sinus surgery: a randomized, double-blind, placebo-controlled study. Laryngoscope. 2010;120(6):1269-73. DOI: 10.1002/lary.20905.

2. Warner G, Burgess AS, Patel S, Martinez-Devesa P, Corbridge R. Otolaryngology and head and neck surgery (Oxford Specialist Handbooks in surgery). Oxford University Press; 2009, p.568-37.

3. Simmen D, Jones NS. Manual of Endoscopic Sinus Surgery and its Extended Applications. Thieme; 2011, p.40-9.

4. Lund V. The nose and paranasal sinuses. In: Gleeson MJ, Clarke RC (eds.). Scott-Brown's Otorhinolaryngology: Head and Neck Surgery. $7^{\text {th }}$ edition. CRC Press; 2009, p. 1481.

5. Kaluskar SK. Endoscopic sinus surgery: a practical approach. Springer Science \& Business Media; 2012, p.79-90.

6. Verim A, Șeneldir L, Naiboğlu B, Karaca CT, kulekci S, Toros SZ, et al. Role of nasal packing in surgical outcome for chronic rhinosinusitis with polyposis. Laryngoscope. 2014;124(7):1529-35. DOI: 10.1002/lary.24543.

7. Hwang CS, Al Sharhan SS, Kim BR, Kim SI, Kim JW, Cho HJ, et al. Randomized controlled trial of steroid-soaked absorbable calcium alginate nasal packing following endoscopic sinus surgery. Laryngoscope. 2018;128(2):311-6. DOI: 10.1002/lary.26871.

8. Sabarinath V, Harish MR, Divakaran S. Triamcinolone impregnated nasal pack in endoscopic sinus surgery: our experience. Indian J Otolaryngol Head Neck Surg. 2017;69(1):88-92. DOI: 10.1007/ s12070-016-1041-x.

9. Hopp ML. Rates of Middle Meatus (MM) synechiae formation post Endoscopic Sinus Surgery (ESS): a double-blind randomized controlled study comparing Silastic and Restora ${ }^{\mathrm{TM}}$ steroid eluting MM spacer. [Internet]. 2015. Available from: https://clinicaltrials.gov/ ct2/show/NCT02627794.

10. Larsen KL, Lange B, Darling P, Jørgensen G, Kjeldsen AD. The validity of nasal endoscopy in patients with chronic rhinosinusitis-An inter-rater agreement study. Clin Otolaryngol. 2018;43(1):144-50.
DOI: $10.1111 /$ coa.12916.

11. Gould D, Kelly D, Goldstone L, Gammon J. Examining the validity of pressure ulcer risk assessment scales: developing and using illustrated patient simulations to collect the data. J Clin Nurs. 2001;10(5):697-706. DOI: 10.1046/j.1365-2702.2001.00525.x.

12. Mohammed T. The role of different materials for prevention of synechiae following endoscopic sinus surgery. Egyptian Journal of Ear, Nose, Throat and Allied Sciences. 2014;15(1):23-8. DOI: 10.1016/j. ejenta.2013.12.001.

13. Anand VK, Tabaee A, Kacker A, Newman JG, Huang C. The role of mitomycin $\mathrm{C}$ in preventing synechia and stenosis after endoscopic sinus surgery. Am J Rhinol. 2004;18(5):311-4.

14. Rudmik L, Schlosser RJ, Smith TL, Soler ZM. Impact of topical nasal steroid therapy on symptoms of nasal polyposis: A meta-analysis. Laryngoscope. 2012;122(7):1431-7. DOI: 10.1002/lary.23259. Epub 2012 Mar 12.

15. Demoly P. Safety of intranasal corticosteroids in acute rhinosinusitis. Am J Otolaryngol. 2008;29(6):403-13. DOI: 10.1016/j.amjoto.2007.11.004.

16. Rowe-Jones JM, Medcalf M, Durham SR, Richards DH, Mackay IS. Functional endoscopic sinus surgery: 5 year follow up and results of a prospective, randomised, stratified, double-blind, placebo controlled study of postoperative fluticasone propionate aqueous nasal spray. Rhinology. 2005;43(1):2-10.

17. Chang EH, Alandejani T, Akbari E, Ostry A, Javer A. Double-blinded, randomized, controlled trial of medicated versus non-medicated merocel sponges for functional endoscopic sinus surgery. J Otolaryngol Head Neck Surg. 2011;40 Suppl 1:S14-9. 